\title{
Peer problems are associated with elevated serum leptin levels in children
}

\author{
G. Kohlboeck ${ }^{1 *}$, M. Romanos ${ }^{2}$, C. Tiesler ${ }^{1,3}$, S. Koletzko ${ }^{3}$, J. Kratzsch ${ }^{4}$, J. Thiery ${ }^{4}$, C.-P. Bauer ${ }^{5}$, \\ A. von Berg ${ }^{6}$, D. Berdel ${ }^{6}$, B. Hoffmann ${ }^{7}$, B. Schaaf ${ }^{8}$, I. Lehmann $^{9}$, O. Herbarth ${ }^{10}$, J. Heinrich ${ }^{1}$ \\ and GINI-plus and LISA-plus study groupst \\ ${ }^{1}$ Helmholtz Zentrum Muenchen, German Research Center for Environmental Health, Institute of Epidemiology I, Neuherberg, Germany \\ ${ }^{2}$ Department of Child and Adolescent Psychiatry and Psychotherapy, University Hospital Wuerzburg, Germany \\ ${ }^{3} \mathrm{Dr}$ von Hauner Children's Hospital, Ludwig-Maximilians-University of Munich, Germany \\ ${ }^{4}$ University Leipzig, Institute of Laboratory Medicine, Clinical Chemistry and Molecular Diagnostics, Germany \\ ${ }^{5}$ Department of Pediatrics, Technical University of Munich, Germany \\ ${ }^{6}$ Department of Pediatrics, Marien-Hospital Wesel, Germany \\ ${ }^{7}$ Leibniz Research Institute for Environmental Medicine, University of Düsseldorf, Germany \\ ${ }^{8}$ Medical Practice for Pediatrics, Bad Honnef, Germany \\ ${ }^{9}$ UFZ-Center for Environmental Research, Leipzig, Germany \\ ${ }^{10}$ University Leipzig, Faculty of Medicine, Environmental Medicine and Hygiene, Leipzig, Germany
}

Background. Leptin is thought to act as an important mediator in stress reactions. To date, no study has examined the association between psychological stress and leptin levels in children. This study aimed to assess the association between emotional symptoms and peer problems and serum leptin levels in children aged 10 years of the two population-based GINI-plus and LISA-plus birth cohorts.

Method. Cross-sectional data from 2827 children aged 10 years were assessed with regard to leptin concentrations in serum and behavioral problems using the parent-reported Strengths and Difficulties Questionnaire (SDQ). Linear regression modeling was applied to determine the likelihood of elevated leptin levels in children with emotional symptoms and peer problems, controlling for socio-economic status (SES), body mass index (BMI), fasting serum leptin levels, pubertal development and sex hormones.

Results. We found that increases in emotional symptoms (exp $\beta_{\text {adj }}=1.03$, s.E. $=0.02, p<0.04$ ) and peer problems $\left(\exp \beta_{\text {adj }}=1.05\right.$, s.E. $\left.=0.01, p=0.0001\right)$ were significantly associated with higher serum leptin levels controlled for BMI and sociodemographic factors. Similar results were found when the fasting serum leptin sample was examined $\left(\exp \beta_{\text {adj }}=1.08\right.$, S.E. $\left.=0.04, p=0.0294\right)$. Gender-stratified analyses showed a significant relationship between serum leptin and peer problems in girls $\left(\exp \beta_{\mathrm{adj}}=1.05\right.$, s.E. $\left.=0.02, p=0.03\right)$, and a borderline significant association in boys $\left(\exp \beta_{\text {adj }}=1.04\right.$, S.E. $\left.=0.02, p=0.05\right)$.

Conclusions. Children with peer problems have higher stress and eat more, acquire a higher body fat mass and thus, through increased leptin resistance, exhibit higher leptin levels.

Received 10 October 2012; Revised 25 February 2013; Accepted 5 March 2013; First published online 8 April 2013

Key words: Behavior problems, depression, epidemiology, HPA axis, leptin, obesity, peer relationship problems, psychopathology, stress.

\section{Introduction}

Leptin is a hormone secreted from adipose tissue that was first discovered to regulate eating, satiety and body weight. In addition to its function in metabolic

\footnotetext{
* Address for correspondence: G. Kohlboeck, Ph.D., Helmholtz Zentrum München, Institut für Epidemiologie, Ingolstädter Landstr. 1, D-85764 Neuherberg, Germany.

(Email: gabi_kohlboeck@yahoo.com)

† Members of the GINI-plus and LISA-plus study groups are listed in the Appendix.
}

control, leptin has been recognized as a more complex hormone involved in regulating the hypothalamicpituitary-adrenal (HPA) axis (Auwerx \& Staels, 1998). Stress is known to activate the HPA axis thus increasing glucocorticoid levels, which in turn stimulate leptin production. Evidence from several studies suggests that experiences of psychological stress may have the potential effect of increasing leptin levels. Higher serum leptin levels have been associated with awareness of higher stress in men (Otsuka et al. 2006), stress-related psychopathological symptoms (Liao et al. 2004), phobic anxiety in women 
(Brennan et al. 2009) and trait anxiety in elderly people (Narita et al. 2008). Depression has shown inconsistent findings, with some studies showing increased leptin levels (Antonijevic et al. 1998; Rubin et al. 2002) but others low levels of leptin (Kraus et al. 2001; Jow et al. 2006). A large population-based study of adults found a fourfold increased risk for elevated leptin levels in men suffering from both depressed mood and social isolation (Häfner et al. 2011).

Bearing in mind that psychosocial stress has been shown to be related to higher leptin levels in adults, this raises the question of whether this finding can also be observed in children. However, apart from studies on eating disorders investigating the metabolic aspect of leptin (Hebebrand et al. 1995; Casanueva et al. 1997; Kopp et al. 1998; Focker et al. 2011; HerpertzDahlmann et al. 2011; Hebebrand \& Albayrak, 2012), no study has examined whether altered leptin levels can be found in children with mental disorders or social stress. Peer problems may be important in this context because, when occurring in children from age 9 to 12 years, it has the potential to cause stress in children. Children at this age are faced with how to get along with others (Erikson, 1959), and how to establish close and enduring interpersonal relationships (Baumeister \& Leary, 1995). These important goals, when threatened, may become sources of stress (e.g. Lazarus \& Folkman, 1984). Thus, we hypothesized that there is an association between peer problems and leptin, and that this association cannot be fully explained by body mass index (BMI). To investigate the relationship between psychosocial stress and leptin levels in children, we determined the relationships between peer problems, emotional symptoms and serum leptin levels in two population-based birth cohorts. In addition, we examine possible confounders of this relationship (gender, BMI, socioeconomic and lifestyle variables, pubertal status and sex hormones), and the potential role of BMI in psychological stress.

\section{Method}

\section{Study population}

Data from two ongoing German birth cohort studies were combined for the present analysis. The German Infant Nutritional Intervention (GINI)-plus study is a prospective birth cohort study that was initiated to investigate the influence of nutritional intervention during infancy, and also air pollution and genetics, on allergy development. Details on study design, recruitment and exclusion criteria have been described elsewhere (Filipiak et al. 2007; von Berg et al. 2007). A total of 3317 children (55.4\%) of the original study population participated in the 10-year follow-up. Loss to follow-up was associated with a lower level of parental education, a negative history of parental atopy, the absence of atopic diseases of the child during the first 2 years of life, and residency in Wesel. The second population-based birth cohort was the 'Influences of lifestyle-related factors on the immune system and the development of allergies in childhood' (LISA-plus) study (Heinrich et al. 2002; Schnabel et al. 2010). A total of 1761 children (56.9\%) of the original study population participated in the 10-year follow-up. Loss to follow-up was strongly associated with a lower level of parental education and residency in Wesel or Leipzig.

Of the 2892 subjects from GINI-plus $(n=1802)$ and LISA-plus $(n=1090)$ whose parents consented to the assessment of blood tests and for whom blood drawings had been performed, data from the Strengths and Difficulties Questionnaire (SDQ) were available for 2827 participants [1443 boys (51\%), 1384 girls (49\%)] of the 10-year follow-up. These data constituted the sample presented in this paper. For both studies we obtained approval by the local ethics committees (Bavarian General Medical Council, University of Leipzig, Medical Council of North-Rhine-Westphalia) and written consent from the participants' families.

\section{Assessment of emotional and peer problems categories}

The parent-reported SDQ (Goodman, 1997; Woerner et al. 2004) is a brief behavioral screening questionnaire for children that comprises 25 items on psychological attributes divided into five subscales: emotional symptoms, conduct problems, hyperactivity/inattention, peer relationship problems, and prosocial behavior. Each item is reported as $0={ }^{\prime}$ not true', $1={ }^{\prime}$ somewhat true' and $2={ }^{\prime}$ certainly true'. For the present analysis, the two subscales emotional symptoms and peer problems were used to cover psychological stress. These subscale scores range from 0 to 10 , where higher scores denote more problems.

\section{Blood assessment}

Serum leptin levels were measured from 2348 nonfasting and 462 fasting blood samples. Fasting blood samples were drawn between 0730 and 0930 hours from children fasted overnight prior to the blood sampling. Blood samples were centrifuged after collection and stored frozen at $-80^{\circ} \mathrm{C}$ until assayed for leptin, estradiol (girls) and testosterone (boys). Leptin concentrations in serum were measured using a commercially available radioimmunoassay (Mediagnost, Germany). The sensitivity of the test was $0.1 \mathrm{ng} / \mathrm{ml}$. Intra- and interassay coefficients of variation $(\mathrm{CVs})$ 
were between $4.0 \%$ and $10.4 \%$ for the range $2.1-38.1 \mathrm{ng} / \mathrm{mL}$ of leptin. Serum samples were measured for testosterone and estradiol by the fully mechanized immunoassay system Modular (Roche, Germany). The analytical sensitivity was $0.087 \mathrm{nmol} / 1$ for testosterone and $18.4 \mathrm{pmol} / \mathrm{l}$ for estradiol. Intra- and interassay $\mathrm{CVs}$ for testosterone measurements were below $4.06 \%$ for a concentration of $6.2 \mathrm{nmol} / 1$ and $2.83 \%$ for $20.2 \mathrm{nmol} / \mathrm{l}$, respectively. For estradiol, intra- and interassay CVs were found to be lower than $5.29 \%$ for a concentration of $378 \mathrm{pmol} / 1$ and lower than $3.56 \%$ for $1941 \mathrm{pmol} / 1$ respectively.

\section{Statistical analysis}

Comparisons of serum leptin levels are reported as mean values with standard deviations (s.D.). A 0.05 level of significance was considered. Distributions of serum leptin levels and SDQ subscales emotional symptoms and peer problems were skewed; logarithmic transformations were applied to normalize the distributions. Linear regression analyses were applied to evaluate the associations between log-transformed serum leptin concentrations (fasting and non-fasting levels) and log-transformed emotional symptoms and peer problems subscale scores, and three adjusted models were tested (model 1: age at blood test, fasting serum leptin sample, gender, study center, parental education, household income, single parent family; model 2: same as model 1 plus BMI; model 3: same as model 2 plus pubertal status). The primary model included all confounders (model 3). To consider the influence of food (Houseknecht \& Spurlock, 2003) and the diurnal rhythm of leptin (Wolthers et al. 1999; Ankarberg-Lindgren et al. 2001), we examined the fasting serum leptin sample $(n=462)$, applying linear regressions controlled for confounders unadjusted and adjusted for confounders. To control for intermediate variables on a causal path from exposure to outcome, a sensitivity analysis was conducted, including all covariates of model 3 plus physical activity, energy intake, and television (TV) viewing/video/computer (PC) game use. To investigate the effect of sex steroids on the emotional/peer problems relationship with leptin, we conducted gender-stratified analyses of the primary model with testosterone in boys and estradiol in girls as additional confounders. The associations between peer problems, leptin and BMI were illustrated by dividing the sample into quartiles of leptin and tertiles of BMI. To investigate whether leptin could account for the association between peer problems and BMI and also for the association between peer problems and emotional symptoms, further sensitivity analyses were conducted with leptin as the confounding variable. Finally, to test whether the association between peer problems, emotional problems and leptin could also be generalized to other stressors, we conducted additional analyses with the SDQ subscales hyperactivity/inattention, conduct problems, and prosocial behavior.

\section{Assessment of confounders}

Based on previously published evidence we adjusted for a variety of factors that could potentially confound the relationship between higher leptin levels and emotional and peer problems. The most important variable that determines leptin concentration is body fat mass (Speakman et al. 2002). However, because of our study design, BMI (weight in $\mathrm{kg} /$ height in $\mathrm{m}^{2}$ ) was used to represent the degree of body fat, and was calculated from weight and height measured by a physician during the clinical examination. We controlled for the influence of food by adjusting for fasting serum leptin levels $(0=$ no, $1=y e s)$ in the total sample. To control the effect of social differences we adjusted for parental educational level, household income and living in a single parent family. Parental education on highest grade completed by either the mother or the father was grouped into low $(<10$ th grade), medium (10th grade) or high ( $>10$ th grade). Net household income was calculated as equivalent income according to the Organization for Economic Cooperation and Development (OECD) guidelines (Hauser, 1988; Sausenthaler et al. 2007) and grouped into low, medium and high tertiles of household income.

To account for differences in leptin concentrations associated with the onset of puberty or the tempo at which this developmental event unfolds (Margetic et al. 2002), age at blood drawing and pubertal status were also included in the primary model. Pubertal status was calculated using the German Pubertal Development Scale (PDS; Petersen et al. 1988; Watzlawik, 2009). Parents rated the maturational status of their child on five markers of pubertal development, and a sum score was calculated based on the number of markers rated as present. Physical activity was assessed by parental report of how many hours their children exercised outside of school per week, and was grouped based on its distribution within the study population as: (0) high ( $\geqslant 75$ th percentile), (1) medium (25th-75th percentile) and (2) low $(<25$ th percentile). We adjusted for total energy intake (in kJ) based on a Food Frequency Questionnaire (FFQ; Stiegler et al. 2010). TV or video viewing and PC use was grouped as: (0) low ( $<1 \mathrm{~h} /$ day), (1) medium (1-2 $\mathrm{h} /$ day) and (2) high ( $\geqslant 3 \mathrm{~h} /$ day). In gender-stratified analyses, serum estradiol levels were added as a confounder for girls and serum testosterone levels for boys. All computations were performed using the 
Table 1. Serum leptin levels by characteristics of the GINI-plus and LISA-plus study sample $(n=2810)$ at the 10-year follow-up

\begin{tabular}{|c|c|c|c|c|}
\hline & \multirow[b]{2}{*}{$n$} & \multicolumn{2}{|c|}{$\begin{array}{l}\text { Serum leptin } \\
\text { level }(\mathrm{ng} / \mathrm{ml})\end{array}$} & \multirow[b]{2}{*}{$p$ value $^{\mathrm{a}}$} \\
\hline & & Mean & S.D. & \\
\hline Study group & & & & 0.3713 \\
\hline GINI-plus & 1758 & 4.4 & 4.3 & \\
\hline LISA-plus & 1052 & 4.2 & 4.7 & \\
\hline Study center & & & & 0.0613 \\
\hline Munich & 1556 & 4.1 & 4.2 & \\
\hline Leipzig & 260 & 4.1 & 4.6 & \\
\hline Bad Honnef & 149 & 4.7 & 5.1 & \\
\hline Wesel & 845 & 4.6 & 4.8 & \\
\hline Gender & & & & $<0.0001$ \\
\hline Male & 1432 & 3.4 & 4.0 & \\
\hline Female & 1378 & 5.2 & 4.8 & \\
\hline Parental education & & & & 0.0007 \\
\hline High (1) & 1847 & 4.1 & 4.3 & \\
\hline Medium (2) & 702 & 4.5 & 4.4 & \\
\hline Low (3) & 146 & 5.5 & 6.1 & \\
\hline Household income & & & & 0.2360 \\
\hline High (1) & 2018 & 4.2 & 4.4 & \\
\hline Medium (2) & 598 & 4.5 & 4.7 & \\
\hline Low (3) & 194 & 4.6 & 4.5 & \\
\hline Physical activity & & & & 0.0003 \\
\hline High $(\geqslant 5 \mathrm{~h} /$ week $)$ & 389 & 3.6 & 3.6 & \\
\hline Medium (2-5 h/week) & 1504 & 4.3 & 4.6 & \\
\hline Low (<2 h/week) & 917 & 4.6 & 4.6 & \\
\hline $\begin{array}{l}\text { Daily TV viewing or video/ } \\
\text { computer game use }\end{array}$ & & & & $<0.0001$ \\
\hline 0 low $(<1 \mathrm{~h})$ & 907 & 3.6 & 3.3 & \\
\hline 1 medium $(1-2 \mathrm{~h})$ & 1567 & 4.5 & 4.8 & \\
\hline 2 high $(\geqslant 3 h)$ & 305 & 5.4 & 5.3 & \\
\hline $\begin{array}{l}\text { PDS: markers of pubertal } \\
\text { development }\end{array}$ & & & & $<0.0001$ \\
\hline 0 none & 1950 & 3.4 & 3.7 & \\
\hline 1 marker & 306 & 5.2 & 5.0 & \\
\hline 2 markers & 157 & 6.7 & 6.1 & \\
\hline 3 markers & 65 & 7.1 & 6.8 & \\
\hline 4 markers & 5 & 5.3 & 3.6 & \\
\hline
\end{tabular}

PDS, Puberty Development Scale; S.D., standard deviation.

${ }^{a} p$ values for distributions between the different categories by the MantelHaenszel $\chi^{2}$ test for categorical data, by ANOVA for continuous data.

statistical software package SAS for Windows, version 9.2 (SAS Institute, USA).

\section{Results}

\section{Subject characteristics}

Subjects were assessed at a mean of 10.54 years (S.D.= 0.25) after baseline survey at birth. Characteristics of the sample and differences in serum leptin levels are presented in Table 1. Higher leptin levels were found among girls, children with low parental education, children with low physical activity, and high TV or PC use. There were also significant differences in leptin levels dependent on markers of pubertal development, indicating higher leptin levels with advanced pubertal development. 
Table 2. Unadjusted and adjusted associations between emotional symptoms and peer problems and serum leptin levels at 10 years of age in the total sample $(n=2810)$

\begin{tabular}{|c|c|c|c|c|c|c|c|c|c|c|c|c|}
\hline \multirow[b]{2}{*}{ SDQ subscale } & \multicolumn{3}{|c|}{ Unadjusted model } & \multicolumn{3}{|c|}{ Model 1} & \multicolumn{3}{|c|}{ Model 2} & \multicolumn{3}{|c|}{ Model 3} \\
\hline & $\exp \beta$ & S.E. & $p$ & $\begin{array}{l}\exp \\
\beta_{\text {adj }}\end{array}$ & S.E. & $p$ & $\begin{array}{l}\exp \\
\beta_{\text {adj }}\end{array}$ & S.E. & $p$ & $\begin{array}{l}\exp \\
\beta_{\text {adj }}\end{array}$ & S.E. & $p$ \\
\hline $\begin{array}{l}\text { Emotional } \\
\text { symptoms }\end{array}$ & 1.0586 & 0.0174 & $<0.0001$ & 1.0377 & 0.0166 & 0.0257 & 1.0258 & 0.0120 & 0.0335 & 1.0190 & 0.0126 & 0.1363 \\
\hline Peer problems & 1.1343 & 0.0186 & $<0.0001$ & 1.1377 & 0.0177 & $<0.0001$ & 1.0513 & 0.0131 & 0.0001 & 1.0448 & 0.0138 & 0.0016 \\
\hline
\end{tabular}

SDQ, Strengths and Difficulties Questionnaire; S.E., standard error.

The regression coefficient $(\beta)$ expresses the change in log-transformed serum leptin that is associated with a $1 \%$ change in the independent variables (SDQ subscales).

Model 1: adjusted for age at blood test, gender, fasting serum leptin, study centre, parental education and household income.

Model 2: adjusted for model 1 factors plus body mass index (BMI) levels.

Model 3: adjusted for model 2 factors plus pubertal status (primary model).

\section{Association between emotional symptoms and peer problems and serum leptin levels in the total sample}

Linear regression, controlling for age, fasting serum leptin levels and socio-demographic background, showed that increases in emotional symptoms (exp $\beta=1.04$, S.E. $=0.02, p<0.03)$ and peer problems (exp $\beta=1.14$, S.E. $=0.02, p<0.0001)$ were positively associated with higher leptin levels (Table 2). Adding BMI, the relationship remained significant for both variables $(\exp \beta=1.03, \quad$ S.E. $=0.02, \quad p<0.04$ and $\exp \beta=1.05$, S.E. $=0.01, p=0.0001$ respectively). Peer problems were significantly associated with leptin when adding pubertal development as a confounder $(\exp \beta=1.05$, S.E. $=0.01, p=0.002$ ), whereas the relationship was attenuated for emotional symptoms. When adding the potential intermediate variables energy intake, physical activity, daily TV viewing/video/PC game use to the full model, the estimate for peer problems did not change. The relationship between peer problems and leptin is illustrated in Fig. 1, which shows mean levels of peer problems in relation to leptin quartiles.

\section{Association between emotional symptoms and peer problems and serum leptin levels in the fasting leptin sample}

Examining the fasting serum leptin sample (Table 3), adjusted linear regression showed that the association between peer problems and serum leptin levels (exp $\beta_{\text {adj }}=1.08$, s.E. $=0.04, p=0.0294$ ) was significant, whereas no significant relationship was found with emotional symptom score $\left(\exp \beta_{\mathrm{adj}}=1.01\right.$, s.E. $\left.=0.03, p=0.85\right)$.

Gender-stratified subanalyses in the total sample showed that, in the primary model plus estradiol (girls) and testosterone (boys) as confounder, serum

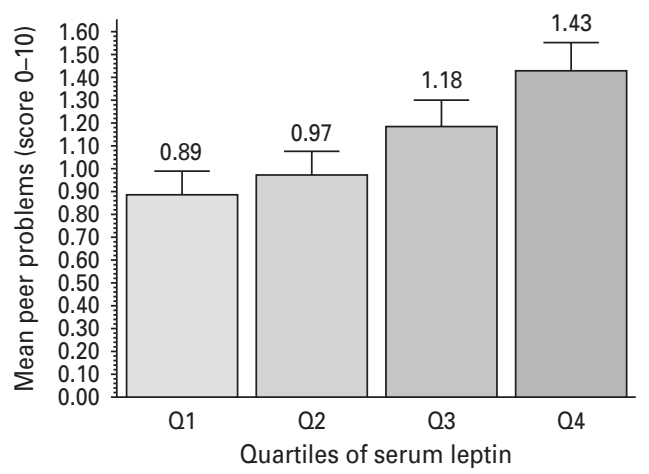

Fig. 1. Mean levels of peer problems measured by the Strengths and Difficulties Questionnaire (SDQ) in relation to leptin quartiles.

leptin levels were positively associated with peer problems ( $\exp \beta_{\mathrm{adj}}=1.05$, S.E. $\left.=0.02, p=0.03\right)$ in girls, whereas the association was borderline statistically significant in boys $\left(\exp \beta_{\text {adj }}=1.04\right.$, S.E. $\left.=0.02, p=0.05\right)$ (data not shown). No significant results were found for emotional symptoms.

\section{Emotional symptoms and peer problems in relation to BMI and leptin}

There was a significant relationship between peer problems and BMI $(p<0.0001)$, independent of age, sociodemographic factors and other confounding factors of model 3. This result is illustrated in Fig. 2, which shows mean levels of peer problems in relation to tertiles of BMI. However, when leptin was added as a confounder into the peer problems/BMI relationship, this association was no longer significant $(p=0.1225)$. By contrast, there was no significant association 
Table 3. Association between emotional symptoms and peer problems and fasting serum leptin levels $(n=462)$

\begin{tabular}{|c|c|c|c|c|c|c|}
\hline \multirow[b]{2}{*}{ SDQ subscale } & \multicolumn{3}{|c|}{ Unadjusted } & \multicolumn{3}{|l|}{ Model 1} \\
\hline & $\exp \beta$ & S.E. & $p$ & $\exp \beta_{\text {adj }}$ & S.E. & $p$ \\
\hline Emotional symptoms & 1.0516 & 0.0470 & 0.2848 & 1.0061 & 0.0335 & 0.8549 \\
\hline Peer problems & 1.2055 & 0.0488 & 0.0001 & 1.0806 & 0.0354 & 0.0294 \\
\hline
\end{tabular}

SDQ, Strengths and Difficulties Questionnaire; S.E., standard error.

The regression coefficient $(\beta)$ expresses the change in log-transformed fasting serum leptin that is associated with a $1 \%$ change in the independent variables (SDQ subscales).

Model 1: adjusted for age at blood test, gender, study centre, parental education, household income, body mass index (BMI levels) and pubertal status (primary model).

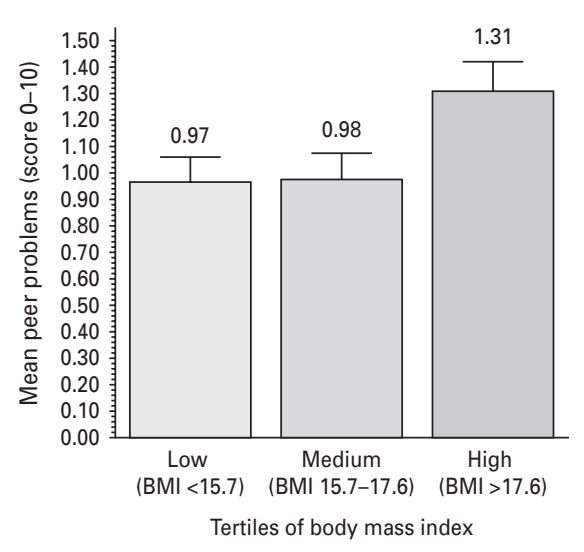

Fig. 2. Mean levels of peer problems measured by the Strengths and Difficulties Questionnaire (SDQ) in relation to body mass index (BMI) tertiles.

between emotional symptoms and BMI, and adding leptin as a confounder did not change the results.

Examining the relationship between emotional symptoms and peer problems and the potential confounding effect of leptin, we found that the emotional symptoms/peer problems relationship remained significant when leptin was added to the full model $(\exp \beta=1.11$, s.E. $=0.02, p<0.0001)$.

We found no significant associations between leptin and any other measures of behavioral problems (SDQ subscales hyperactivity/inattention, conduct problems, and prosocial behavior) (data not shown).

\section{Discussion}

Peer problems at age 10 years were found to be significantly associated with elevated serum leptin levels controlled for fasting serum leptin levels, socioeconomic status (SES), BMI and pubertal development. The association between leptin and peer problems remained statistically significant in the fasting serum leptin sample, and when stratified by gender.
We know of no other study that has examined the association between mental health problems or social stress and leptin levels in children. In agreement with the results from previous studies on leptin concentration and body weight, we found that serum leptin concentrations were dependent on gender and BMI (Hassink et al. 1996; Blum et al. 1997; Garcia-Mayor et al. 1997). Our findings of a more advanced pubertal development together with higher leptin levels are also in agreement with a study showing leptin concentrations to be higher in post-pubertal girls than in prepubertal girls (Demerath et al. 1999). Our result of lower SES being associated with higher leptin levels is in agreement with the Avon Longitudinal Study of Parents and Children (ALSPAC) investigating socio-economic inequalities in cardiovascular risk factors at age 10 years (Howe et al. 2010).

Although we hypothesized that emotional symptoms might be associated with leptin, we did not observe a significant association after adjustment for confounding variables or in the fasting serum leptin sample, indicating that emotional symptoms are associated with leptin to a lower degree in children. However, there is inconsistent evidence for depression and its association with leptin levels among adult populations (Antonijevic et al. 1998; Kraus et al. 2001; Rubin et al. 2002; Esel et al. 2005; Jow et al. 2006; Yang et al. 2007; Pasco et al. 2008; Lawson et al. 2011). Our results of a differential effect of emotional symptoms and peer problems may indicate that both categories capture different forms of social or psychological stress-related problems.

Our finding of a more pronounced leptin/peer stress association in girls reflects a gender-specific stress response. The greater total body fat in women could potentially contribute to the heightened association between leptin and stress responses (Rosenbaum et al. 1996). Another explanation may be that the girls in our study were experiencing higher levels of peer stress compared to the boys. Investigating social stress 
at entry into adolescence, a previous study found that girls who start puberty show higher physiological stress reactions (cortisol levels) than girls who mature later (Sontag et al. 2008).

Assuming that the SDQ subcategory peer problems is indicative of high social stress, our finding of peer problems being related to leptin levels is consistent with prior findings that elevated circulating levels of leptin have been reported in people with high levels of perceived daily stress (Otsuka et al. 2006), in children of low socio-economic position (Howe et al. 2010), in people suffering from depression (Raison et al. 2006), in men suffering from social isolation (Häfner et al. 2011) and in patients with post-traumatic stress disorder (Liao et al. 2004). The high leptin levels found in these studies are explained by activation of the stress response system of the HPA axis. Therefore, one explanation for our results is that the elevated leptin levels may be interpreted as a potential adaptive response to psychological stress. Leptin might have been increased to attenuate the stress response resulting from persistent HPA axis activation by chronic social stress (Otsuka et al. 2006). It is possible that peer problems reflect a 'defeat' stress response that results in activation of the HPA axis, which mediates an increase in glucocorticoid levels. The increased levels of glucocorticoids are capable of stimulating the synthesis and secretion of leptin. Several studies have investigated relationships between peer stress and HPA axis activation by measuring saliva cortisol (glucocorticoids) levels. Peer rejection (Gunnar et al. 2003; Peters et al. 2011), peer conflict (Flinn \& England, 1995; Flinn, 1999) and peer victimization (Vaillancourt et al. 2008) were all found to be associated with cortisol levels. Future studies are required that evaluate cortisol levels to examine whether social stress is capable of stimulating the synthesis and secretion of leptin. However, leptin might be a potential biomarker to provide additional information on the psychological and social well-being of children.

A plausible explanation for the peer problems/leptin association may be that BMI and obesity have a major contribution to social stress. Children with stress eat more, acquire a higher body fat mass, and thus through increased leptin resistance exhibit higher leptin levels. This agrees with evidence that suggests that people who are more responsive to psychological stress are at an increased risk of developing obesity (Bjorntorp, 2001; Brydon et al. 2007). However, the biological mechanisms underlying this phenomenon are poorly understood. Stress might promote obesity and contribute to abdominal obesity by stimulating increases in leptin. Our results show that peer problems are closely related to BMI levels. Thus, the higher leptin levels in our study may be the result of higher fat mass in those children with obesity who also have a higher prevalence of psychological stress. Subjects with higher fat mass have high leptin levels (Considine et al. 1996) because of a presumed resistance to the appetite suppressant and metabolic effects of leptin ('leptin resistance').

However, up to now the direction of the peer problems/obesity relationship remains unclear, that is whether psychological stress causes obesity or whether obesity has an effect on social stress. The results from population-based studies have shown that overweight/obesity is related to peer problems in children, whereas other features of psychopathology, particularly emotional disorders and conduct disorders, did not display strong associations (Boneberger et al. 2009; Drukker et al. 2009; Pitrou et al. 2010). Obese children are more picked on or bullied by other children (Lumeng et al. 2010), and overweight children experience stigmatization as early as age 6 (Pitrou et al. 2010).

Our result that other potential stressors (other subdomains of behavioral problems) failed to show any association with leptin levels suggests that this relationship is specific to this type of stressful problem. Thus, peer problems could be specific for HPA activation. Our speculation is also supported by a previous study measuring cortisol levels in children (Peters et al. 2011). The findings of this study indicate that peer group processes are related to HPA activation because children who were excluded by their classmates had elevated cortisol levels. This effect was weaker for children with more friends or better friendships. Thus, we may speculate that activation of the HPA stress response system resulting in higher leptin levels is particularly sensitive to feelings of being rejected and isolated from peers in middle childhood, but is less influenced by other potential stressors.

\section{Strengths and limitations}

The strength of our study lies in the inclusion of a wide range of potential confounders, including several socio-economic indicators such as parental income and single parent family, along with lifestyle factors, pubertal development and sex hormones. Given the current paucity of available data for children, these findings provide the first contribution of leptin to the field of HPA axis response to psychological stress in children.

Our study also has limitations, first because the cross-sectional design only provides associations between variables, and not causal relationships. Second, although the study is population based, the results may not be fully representative for the total population with regard to sociodemographic 
characteristics and non-random loss to follow-up. A sensitivity analysis revealed that children from lower socio-economic background were slightly more likely to drop out over time (data not shown) (Sausenthaler et al. 2007). Although our population has an over-representation of high SES families, we found that peer problems were associated with increased leptin levels. As both education and income are associated with leptin levels, we may therefore have underestimated the effects. Third, our study design meant that we were unable to obtain fasting serum leptin samples of all children, although it is generally accepted that the effect of individual meals on serum leptin levels is small (Birketvedt et al. 1999). The reason to also use non-fasting leptin was that we wanted to determine the association between leptin and emotional symptoms/peer problems in a large population-based sample. The question of whether leptin from non-fasting samples could be useful for these associations has not been addressed in previous studies, and might therefore be of interest. Another reason to consider non-fasting levels, even though they are influenced by diet, is that leptin levels may be more representative of average circulating levels, especially in non-fasting subjects. Fasting samples may be not representative of a subject's normal daily physiological state. Two studies (Hancox \& Landhuis, 2011; Khafaji et al. 2012) have performed repeated measurements of blood serum samples among fasting and non-fasting subjects, and reported correlations in the region of 0.95 for leptin levels, suggesting good reliability. Hancox \& Landhuis (2001) conclude that non-fasting leptin levels are probably sufficient for population-based research.

Because we accounted for fasting blood samples as a confounder, and the results showed a significant peer problems/leptin relationship in those 462 children who fasted overnight prior to the blood sampling, we probably eliminated bias due to the influence of food. Fourth, in the non-fasting blood samples diurnal variations in concentrations may have resulted in random misclassification. However, because fasting serum samples were drawn between 0730 and $0930 \mathrm{~h}$, which is the time of day when circulating leptin concentrations would be expected to be at their nadir (Schoeller et al. 1997; van Aggel-Leijssen et al. 1999), it seems unlikely that diurnal variation in leptin concentrations would have had a significant impact on the relationship between leptin and peer problems observed in the present study. In general, the normal within-individual diurnal variations of leptin are of a much smaller magnitude than the inter-individual variation determined by significant differences in body adiposity (Brannian et al. 2001). Fifth, although we adjusted for BMI in our analyses, we were unable to adjust for body fat mass, which reflects the degree of adiposity and is a stronger predictor of leptin levels. Although it is generally accepted that BMI as a global indicator of body fat is a predictor of serum leptin (Considine et al. 1996; Sumner et al. 1998), there may be a residual confounding of fat mass not explained by BMI. Sixth, our findings may have been limited by the fact that emotional symptoms and peer problems were assessed by parental report, rather than by children self-report. However, the measures of 'emotional symptoms' and 'peer problems' used for this study have been well validated to assess behavioral problems among children (Goodman, 1997; Woerner et al. 2004). Finally, our study design meant that an evaluation of cortisol levels in our study population was not possible, although this would have been helpful for a hypothetical explanation that higher leptin levels are an adaptive response to psychological stress.

\section{Conclusions}

Our results indicate that, in children, higher leptin levels are associated with psychological stress, and with peer problems in particular. Elevated leptin levels might also be the result of higher fat mass in those children who have a higher prevalence of peer problems secondary to their obesity problem. Future studies are required to investigate whether body fat mass confounds the association between leptin and peer problems. Our results point to a potential influence of social relationships during childhood on the risk of developing obesity and metabolic alterations later in life.

\section{Appendix \\ GINI-plus Study Group}

The GINI-plus Study Group comprises the Helmholtz Zentrum München, German Research Center for Environmental Health, Institute of Epidemiology, Munich (Heinrich J, Wichmann HE, Sausenthaler S, Zutavern A, Chen, Chih-Mei, Schnappinger M, Rzehak P); Department of Pediatrics, Marien-Hospital, Wesel (Berdel D, von Berg A, Beckmann C, Groß I); Department of Pediatrics, Ludwig Maximilians University, Munich (Koletzko S, Reinhardt D, KraussEtschmann S); Department of Pediatrics, Technical University, Munich (Bauer CP, Brockow I, Grübl A, Hoffmann U); IUF - Institut für Umweltmedizinische Forschung at the Heinrich-Heine-University, Düsseldorf (Krämer U, Link E, Cramer C); Centre for Allergy and Environment, Technical University, Munich (Behrendt H). 


\section{LISA-plus Study Group}

The LISA-plus Study Group consists of the following: Helmholtz Zentrum München, German Research Center for Environmental Health, Institute of Epidemiology, Munich (Heinrich J, Wichmann HE, Sausenthaler S, Chen CM, Schnappinger M); Department of Pediatrics, Municipal Hospital 'St.Georg', Leipzig (Borte M, Diez U), Marien-Hospital Wesel, Department of Pediatrics, Wesel (von Berg A, Beckmann C, Groß I); Pediatric Practice, Bad Honnef (Schaaf B); Helmholtz Centre for Environmental Research UFZ, Department of Environmental Immunology/Core Facility Studies, Leipzig (Lehmann I, Bauer M, Gräbsch C, Röder S, Schilde M); University of Leipzig, Institute of Hygiene and Environmental Medicine, Leipzig (Herbarth O, Dick C, Magnus J); IUF - Institut für Umweltmedizinische Forschung, Düsseldorf (Krämer U, Link E, Cramer C); Technical University Munich, Department of Pediatrics, Munich (Bauer CP, Hoffmann U); ZAUM - Center for Allergy and Environment, Technical University, Munich (Behrendt $\mathrm{H}$, Grosch J, Martin F).

\section{Acknowledgments}

This research was funded by grants 01 EG 9732 and 01 EG 9705/2 (LISA study) and 01 EE 9401-4 (GINI study) from the Federal Ministry for Education, Science, Research, and Technology, FKZ 20462296 from the Federal Ministry of Environment, and LudwigMaximilians-University's innovative research priority project MC-Health.

We thank all the families who participated in the GINI-plus study and LISA-plus study. Furthermore, we thank all members of the GINI-plus and LISAplus study groups for their excellent work.

\section{Declaration of Interest}

None.

\section{References}

Ankarberg-Lindgren C, Dahlgren J, Carlsson B, Rosberg S, Carlsson L, Wikland KA, Norjavaara E (2001). Leptin levels show diurnal variation throughout puberty in healthy children, and follow a gender-specific pattern. European Journal of Endocrinology 145, 43-51.

Antonijevic IA, Murck H, Frieboes RM, Horn R, Brabant G, Steiger A (1998). Elevated nocturnal profiles of serum leptin in patients with depression. Journal of Psychiatric Research 32, 403-410.

Auwerx J, Staels B (1998). Leptin. Lancet 351, 737-742.

Baumeister RF, Leary MR (1995). The need to belong: desire for interpersonal attachments as a fundamental human motivation. Psychological Bulletin 117, 497-529.

Birketvedt GS, Florholmen J, Sundsfjord J, Osterud B, Dinges D, Bilker W, Stunkard A (1999). Behavioral and neuroendocrine characteristics of the night-eating syndrome. Journal of the American Medical Association 282, 657-663.

Bjorntorp P (2001). Do stress reactions cause abdominal obesity and comorbidities? Obesity Reviews 2, 73-86.

Blum WF, Englaro P, Hanitsch S, Juul A, Hertel NT, Müller J, Skakkebæk NE, Heiman ML, Birkett $M$, Attanasio AM, Kiess W, Rascher W (1997). Plasma leptin levels in healthy children and adolescents: dependence on body mass index, body fat mass, gender, pubertal stage, and testosterone. Journal of Clinical Endocrinology and Metabolism 82, 2904-2910.

Boneberger A, von Kries R, Milde-Busch A, Bolte G, Rochat MK, Ruckinger S (2009). Association between peer relationship problems and childhood overweight/obesity. Acta Paediatrica 98, 1950-1955.

Brannian JD, Schmidt SM, Kreger DO, Hansen KA (2001). Baseline non-fasting serum leptin concentration to body mass index ratio is predictive of IVF outcomes. Human Reproduction 16, 1819-1826.

Brennan AM, Fargnoli JL, Williams CJ, Li T, Willett W, Kawachi I, Qi L, Hu FB, Mantzoros CS (2009). Phobic anxiety is associated with higher serum concentrations of adipokines and cytokines in women with diabetes. Diabetes Care 32, 926-931.

Brydon L, Wright CE, O'Donnell K, Zachary I, Wardle J, Steptoe A (2007). Stress-induced cytokine responses and central adiposity in young women. International Journal of Obesity 32, 443-450.

Casanueva FF, Dieguez C, Popovic V, Peino R, Considine RV, Caro JF (1997). Serum immunoreactive leptin concentrations in patients with anorexia nervosa before and after partial weight recovery. Biochemical and Molecular Medicine 60, 116-120.

Considine RV, Sinha MK, Heiman ML, Kriauciunas A, Stephens TW, Nyce MR, Ohannesian JP, Marco CC, McKee LJ, Bauer TL, Caro JF (1996). Serum immunoreactive-leptin concentrations in normal-weight and obese humans. New England Journal of Medicine 334, 292-295.

Demerath EW, Towne B, Wisemandle W, Blangero J, Chumlea WC, Siervogel RM (1999). Serum leptin concentration, body composition, and gonadal hormones during puberty. International Journal of Obesity and Related Metabolic Disorders 23, 678-685.

Drukker M, Wojciechowski F, Feron FJM, Mengelers R, van Os J (2009). A community study of psychosocial functioning and weight in young children and adolescents. International Journal of Pediatric Obesity 4, 91-97.

Erikson EH (1959). Identity and the Life Cycle. International Universities Press: New York.

Esel E, Ozsoy S, Tutus A, Sofuoglu S, Kartalci S, Bayram F, Kokbudak Z, Kula M (2005). Effects of antidepressant treatment and of gender on serum leptin levels in patients with major depression. Progress in 
Neuro-Psychopharmacology and Biological Psychiatry 29, 565-570.

Filipiak B, Zutavern A, Koletzko S, von Berg A, Brockow I, Grubl A, Berdel D, Reinhardt D, Bauer CP, Wichmann HE, Heinrich J (2007). Solid food introduction in relation to eczema: results from a four-year prospective birth cohort study. Journal of Pediatrics 151, 352-358.

Flinn MV (1999). Family environment, stress and health during childhood. In Hormones, Health and Behavior: A Socio-ecological and Lifespan Perspective (ed. C. Panter-Brick and C. M. Worthman), pp. 105-138. Cambridge University Press: Cambridge.

Flinn MV, England BG (1995). Childhood stress and family environment. Current Anthropology 36, 854-866.

Focker M, Timmesfeld N, Scherag S, Buhren $K$, Langkamp M, Dempfle A, Sheridan EM, de Zwaan M, Fleischhaker C, Herzog W, Egberts K, Zipfel S, Herpertz-Dahlmann B, Hebebrand J (2011). Screening for anorexia nervosa via measurement of serum leptin levels. Journal of Neural Transmission 118, 571-578.

Garcia-Mayor RV, Andrade MA, Rios M, Lage M, Dieguez C, Casanueva FF (1997). Serum leptin levels in normal children: relationship to age, gender, body mass index, pituitary-gonadal hormones, and pubertal stage. Journal of Clinical Endocrinology and Metabolism 82, 2849-2855.

Goodman R (1997). The Strengths and Difficulties Questionnaire: a research note. Journal of Child Psychology and Psychiatry 38, 581-586.

Gunnar MR, Sebanc AM, Tout K, Donzella B, van Dulmen MM (2003). Peer rejection, temperament, and cortisol activity in preschoolers. Developmental Psychobiology 43, 346-358.

Häfner S, Zierer A, Emeny RT, Thorand B, Herder C, Koenig W, Rupprecht R, Ladwig KH (2011). Social isolation and depressed mood are associated with elevated serum leptin levels in men but not in women. Psychoneuroendocrinology 36, 200-209.

Hancox RJ, Landhuis CE (2011). Correlation between measures of insulin resistance in fasting and nonfasting blood. Diabetology and Metabolic Syndrome 3, 23.

Hassink SG, Sheslow DV, de Lancey E, Opentanova I, Considine RV, Caro JF (1996). Serum leptin in children with obesity: relationship to gender and development. Pediatrics 98, 201-203.

Hauser R (1988). Adequacy and Poverty Among the Retired. Ageing Working Paper (AWP) No. 3.2. Organization for Economic Co-operation and Development (OECD): Paris.

Hebebrand J, Albayrak O (2012). Leptin treatment of patients with anorexia nervosa? The urgent need for initiation of clinical studies. European Child and Adolescent Psychiatry 21, 63-66.

Hebebrand J, van der Heyden J, Devos R, Köpp W, Herpertz S, Remschmidt H, Herzog W (1995). Plasma concentrations of obese protein in anorexia nervosa. Lancet 346, 1624-1625.

Heinrich J, Bolte G, Holscher B, Douwes J, Lehmann I, Fahlbusch B, Bischof W, Weiss M, Borte M, Wichmann HE (2002). Allergens and endotoxin on mothers' mattresses and total immunoglobulin E in cord blood of neonates. European Respiratory Journal 20, 617-623.

Herpertz-Dahlmann B, Buhren K, Seitz J (2011). Anorexia nervosa in childhood and adolescence: course and significance for adulthood [in German]. Nervenarzt 82, 1093-1099.

Houseknecht KL, Spurlock ME (2003). Leptin regulation of lipid homeostasis: dietary and metabolic implications. Nutrition Research Reviews 16, 83-96.

Howe LD, Galobardes B, Sattar N, Hingorani AD, Deanfield J, Ness AR, Davey-Smith G, Lawlor DA (2010). Are there socioeconomic inequalities in cardiovascular risk factors in childhood, and are they mediated by adiposity? Findings from a prospective cohort study. International Journal of Obesity 34, 1149-1159.

Jow GM, Yang TT, Chen CL (2006). Leptin and cholesterol levels are low in major depressive disorder, but high in schizophrenia. Journal of Affective Disorders 90, 21-27.

Khafaji HA, Bener A, Osman M, Al Merri A, Al Suwaidi J (2012). The impact of diurnal fasting during Ramadan on the lipid profile, hs-CRP, and serum leptin in stable cardiac patients. Vascular Health and Risk Management 8, 7-14.

Kopp W, Blum WF, Ziegler A, Mathiak K, Lubbert H, Herpertz S, Deter HC, Hebebrand J (1998). Serum leptin and body weight in females with anorexia and bulimia nervosa. Hormone and Metabolic Research 30, 272-275.

Kraus T, Haack M, Schuld A, Hinze-Selch D, Pollmacher T (2001). Low leptin levels but normal body mass indices in patients with depression or schizophrenia.

Neuroendocrinology 73, 243-247.

Lawson EA, Miller KK, Blum JI, Meenaghan E, Misra M, Eddy KT, Herzog DB, Klibanski A (2011). Leptin levels are associated with decreased depressive symptoms in women across the weight spectrum, independent of body fat. Clinical Endocrinology 6, 520-525.

Lazarus RS, Folkman S (eds) (1984). Stress, Appraisal, and Coping. Springer: New York, NY.

Liao SC, Lee MB, Lee YJ, Huang TS (2004). Hyperleptinemia in subjects with persistent partial posttraumatic stress disorder after a major earthquake. Psychosomatic Medicine 66, 23-28.

Lumeng JC, Forrest P, Appugliese DP, Kaciroti N, Corwyn RF, Bradley RH (2010). Weight status as a predictor of being bullied in third through sixth grades. Pediatrics 125, 1301-1307.

Margetic S, Gazzola C, Pegg GG, Hill RA (2002). Leptin: a review of its peripheral actions and interactions. International Journal of Obesity and Related Metabolic Disorders 26, 1407-1433.

Narita K, Murata T, Hamada T, Kosaka H, Sudo S, Mizukami K, Yoshida H, Wada Y (2008). Associations between trait anxiety, insulin resistance, and atherosclerosis in the elderly: a pilot cross-sectional study.

Psychoneuroendocrinology 33, 305-312.

Otsuka R, Yatsuya H, Tamakoshi K, Matsushita K, Wada K, Toyoshima H (2006). Perceived psychological stress and serum leptin concentrations in Japanese men. Obesity 14, 1832-1838. 
Pasco JA, Jacka FN, Williams LJ, Henry MJ, Nicholson GC, Kotowicz MA, Berk M (2008). Leptin in depressed women: cross-sectional and longitudinal data from an epidemiologic study. Journal of Affective Disorders 107, 221-225.

Peters E, Riksen-Walraven J, Cillessen A, de Weerth C (2011). Peer rejection and HPA activity in middle childhood: friendship makes a difference. Child Development 82, 1906-1920.

Petersen AC, Crockett L, Richards M, Boxer A (1988). A self-report measure of pubertal status: reliability, validity, and initial norms. Journal of Youth and Adolescence 17, 117-133.

Pitrou I, Shojaei T, Wazana A, Gilbert F, Kovess-Masfety V (2010). Child overweight, associated psychopathology, and social functioning: a French school-based survey in 6- to 11-year-old children. Obesity 18, 809-817.

Raison CL, Capuron L, Miller AH (2006). Cytokines sing the blues: inflammation and the pathogenesis of depression. Trends in Immunology 27, 24-31.

Rosenbaum M, Nicholson M, Hirsch J, Heymsfield SB, Gallagher D, Chu F, Leibel RL (1996). Effects of gender, body composition, and menopause on plasma concentrations of leptin. Journal of Clinical Endocrinology and Metabolism 81, 3424-3427.

Rubin RT, Rhodes ME, Czambel RK (2002). Sexual diergism of baseline plasma leptin and leptin suppression by arginine vasopressin in major depressives and matched controls. Psychiatry Research 113, 255-268.

Sausenthaler S, Kompauer I, Mielck A, Borte M, Herbarth O, Schaaf B, von Berg A, Heinrich J (2007). Impact of parental education and income inequality on children's food intake. Public Health Nutrition 10, 24-33.

Schnabel E, Sausenthaler S, Schaaf B, Schafer T, Lehmann I, Behrendt H, Herbarth O, Borte M, Kramer U, von Berg A, Wichmann HE, Heinrich J (2010). Prospective association between food sensitization and food allergy: results of the LISA birth cohort study. Clinical and Experimental Allergy 40, 450-457.

Schoeller DA, Cella LK, Sinha MK, Caro JF (1997). Entrainment of the diurnal rhythm of plasma leptin to meal timing. Journal of Clinical Investigation 100, 1882-1887.

Sontag LM, Graber JA, Brooks-Gunn J, Warren MP (2008). Coping with social stress: implications for psychopathology in young adolescent girls. Journal of Abnormal Child Psychology 36, 1159-1174.

Speakman JR, Stubbs RJ, Mercer JG (2002). Does body mass play a role in the regulation of food intake? Proceedings of the Nutrition Society 61, 473-487.

Stiegler P, Sausenthaler S, Buyken AE, Rzehak P, Czech D, Linseisen J, Kroke A, Gedrich K, Robertson C, Heinrich J (2010). A new FFQ designed to measure the intake of fatty acids and antioxidants in children. Public Health Nutrition 13, 38-46.

Sumner AE, Falkner B, Kushner H, Considine RV (1998). Relationship of leptin concentration to gender, menopause, age, diabetes, and fat mass in African Americans. Obesity Research 6, 128-133.

Vaillancourt T, Duku E, Decatanzaro D, Macmillan H, Muir C, Schmidt LA (2008). Variation in hypothalamic-pituitary-adrenal axis activity among bullied and non-bullied children. Aggressive Behavior 34, 294-305.

van Aggel-Leijssen DP, van Baak MA, Tenenbaum R, Campfield LA, Saris WH (1999). Regulation of average $24 \mathrm{~h}$ human plasma leptin level; the influence of exercise and physiological changes in energy balance. International Journal of Obesity and Related Metabolic Disorders 23, 151-158.

von Berg A, Koletzko S, Filipiak-Pittroff B, Laubereau B, Grubl A, Wichmann HE, Bauer CP, Reinhardt D, Berdel D (2007). Certain hydrolyzed formulas reduce the incidence of atopic dermatitis but not that of asthma: three-year results of the German Infant Nutritional Intervention Study. Journal of Allergy and Clinical Immunology 119, 718-725.

Watzlawik M (2009). The acquisition of puberty status using the Pubertal Development Scale. First steps in the evaluation of a German translation [in German]. Diagnostica 55, 55-65.

Woerner W, Becker A, Rothenberger A (2004). Normative data and scale properties of the German parent SDQ. European Child and Adolescent Psychiatry 13, 3-10.

Wolthers OD, Heuck C, Skjaerbaek C (1999). Diurnal rhythm in serum leptin. Journal of Pediatric Endocrinology and Metabolism 12, 863-866.

Yang K, Xie G, Zhang Z, Wang C, Li W, Zhou W, Tang Y (2007). Levels of serum interleukin (IL)-6, IL-1 $\beta$, tumour necrosis factor- $\alpha$ and leptin and their correlation in depression. Australian and New Zealand Journal of Psychiatry 41, 266-273. 